\title{
Activated Sludge: Decolorization and Degradation of Textile Dye Reactive Orange HE2R
}

\author{
Pratibha S. Patil \\ Department of Biotechnology, Shivaji University, Kolhapur, Maharashtra, India, 416004
}

\begin{abstract}
At lab scale develop an activated sludge and decolorize three tested textile dyes Reactive Red 198, Reactive Orange HE2R and Navy Blue HE2R 13, 17 and 8\% respectively within 120 h. In presence of Glucose (51\%)and yeast extract (98\%) decolorization of Reactive Orange HE2R dye observed within $24 \mathrm{~h}$. The significantly involved laccase and NADH-DCIP reductase in dye decolorization. The analytical studies like UV-Visspectroscopy,FTIRand HPLC confirmed the degradation of Reactive Orange HE2R. GC-MS data has been proposed the probable dye degraded pathway and metabolites formed identifiedas 2-amino butane 4-sulpho aniline and sulphoaniline.
\end{abstract}

Keywords: Activated sludge,Reactive Orange HE2R,Biodegradation,Enzyme and GCMS

\section{Introduction}

Every Industrial plant utilizes raw materials which are converted to a variety of products. Depending on the industrial process, varying amounts of a range of waste materials are produce. Typical waste might include unconsumed inorganic and other suspended solids, wastes, wash waters from cleansing operations, water containing traces of solvents, acids, alkali's etc. Historically, it was possible to dispose of wastes directly to a convenient area of land or into a nearby water course.

Textile industries produce multi-component wastes (dyes, starches, enzymes, fats, greases, waxes, surfactants, resins, chlorinated organic compounds etc.) depending upon the wet processes involved [1-2]. The textile industries effluents that contain several types of chemicals such as dispersants, leveling agents, acids, alkalis, carriers and various dyes [3]. It changes the $\mathrm{pH}$, increases the chemical oxygen demand and biochemical oxygen demand and gives the rivers intense colorations [4].

The basic activated-sludge process consists of aerating and agitating the effluent in the presence of a flocculated suspension of microorganisms on particulate organic matter. This process was first reported by ArdenandLockette[5] and is now most widely used biological treatment process for both domestic and industrial waste waters. Activated sludge process alone has been use for the treatment of a variety of industrial dyes containing wastewaters and colored compounds. The Activated sludge process is a biological process of wastewater treatment that is performed by a variable and mixed community of microorganisms in an aerobic aquatic environment. The activated sludge process is a suspended-culture system that has been in use since the early 1900s. The process derives its name from the fact that settled sludge containing living, or active, microorganisms is returned to the reactor to increase the available biomass and speed up the reactions process; which is aerobic, with oxygen being supplied by dissolution from entrained air. This is the most versatile biological oxidation method working for the treatment of textile waste water.
The treatment of a variety of industrial wastewaters containing dyes and colored compounds has been used activated sludge process alone. The nature of dyes is very complex with respect to their charge, substituted groups and hydrophobicity. The sorption of dye depends upon the type of dye and environmental conditions like the hardness and sludge concentration [6].Conventional biological treatments such as activated sludge and aerated lagoons reduce COD load and toxicity of bleach plant effluents but cannot remove color, which is due mainly to high molecular mass chloroorganic materials in the effluent [7]. Activated sludge operating conditions are then modified for the maximum removal of the color. In case of anaerobic processes, it very difficult to mineralize the dye degraded metabolites, the biological approach is to use an integrated anaerobic-aerobic process for decolorization of colors. Seshadri et al. [8] reported, for the color removing use the anaerobic fluidized bed followed by an aerobic activated sludge system.

Only few bacteria with specialized azo dye reducing enzymes were found to degrade azo dyes under fully aerobic conditions [9-10]. Aerobic biodegradationis the breakdown of organic contaminants by microorganisms when oxygen is present. Aerobic bacteria use oxygen as an electron acceptor, and break down organic chemicals into smaller organic compounds, often producing carbon dioxide and water as the final product. Under aerobic conditions azo dyes are not readily metabolized, although the ability of bacteria with special reducing enzymes to aerobically degrade certain azo dyes was reported [11].

A few bacterial species can dye waste decolorize aerobically, by activated sludge or in fixed film systems [12]. Churchley et al. [13] reported that RB4 dye was biologically eliminated due to sorption on an aerobic, activated sludge culture. Aksu[14] investigated the biosorption of RB2 (an anthraquinone dye with a monochlorotriazinyl reactive group), onto pre-dried activated sludge.

Combined anaerobic and aerobic bacterial biodegradation of azo dyes has its applications in wastewater treatment processes. An alternating anaerobic-aerobic treatment system is responsible for the total degradation of dyes [15]. 


\section{International Journal of Science and Research (IJSR) \\ ISSN (Online): 2319-7064 \\ Index Copernicus Value (2013): 6.14 | Impact Factor (2015): 6.391}

Recently, several high rate anaerobic/aerobic reactors have been evaluated to get high decolorization rates and mineralization of dyes, such as anaerobic/aerobic sequencing batch reactor (SBR) [16]. Also, the some researchers reported the bacteria strains decolorize dye, either in purecultures or in consortia [17-21].

The present study reports the degradation of Reactive orange HE2R by an activated sludge. Reactive Orange HE2R is a reactive azo dye and has a large consumption rate in the textile dyeing processes at Ichalkaranji, $\mathrm{MH}$, India. The role of enzymes examined in the degradation process. Reactive Orange HE2R degraded metabolitesby an activated sludge was analyzed by analytic techniques.

\section{Materials and Methods}

\subsection{Activated Sludge Development}

The sludge was collected from textile wastewater disposal site, Ichalkaranji India. Sludge was activated in container having $6 \mathrm{~cm}$ diameter, 3 feet height and 1lit capacity. The $10 \%$ sludge was mixed with water in the container and 5 ppm peptone waterand was added as anenergysource at room temperature $\left(32 \pm 1^{\circ} \mathrm{C}\right)$. Aeration was continued for seven days, the number of bacterial cells was counted by nephelometry described by Talwar[22]. The turbidity of a test suspension is compared with the respective turbidities of series of ten standard tubes containing $\mathrm{BaCl}_{2}$ (1\%) and $\mathrm{H}_{2} \mathrm{SO}_{4}$ (1\%). The turbidities of these standard tubes correspond to varying concentrations of bacteria.

\subsection{Dye decolorization experiment}

After theseven days activated sludge,100mlwas collected into $250 \mathrm{ml}$ conical flask and Reactive Orange HE2R (30 mg $\mathrm{l}^{-1}$ ) was added and kept at room temperature. Then flask was observed for decolorization. After decolorization withdraw $3 \mathrm{ml}$ sample and detect optical density at $490 \mathrm{~nm}$. Decolorization was calculated in percentage. $\%$ Decolorization $=(\mathrm{A}-\mathrm{B}) / \mathrm{A} \times 100$. Where, $\mathrm{A}$ is initial absorbance of dye, $\mathrm{B}$ is final absorbance dye.

\subsection{Repeated dye decolorization study}

The repetitive dye decolorization capacity of the sludge was (repeated use) studied by addition of Reactive Orange HE2R (30 $\mathrm{mg} 1^{-1}$ ) at each cycle. After every24 h dye was added to flask and decolorization was observed. This procedure was done until the no decolorization of dye observed. After every decolorization cycle O.D was taken at $490 \mathrm{~nm}$ and results were noted down.

\subsection{Enzyme status}

The enzyme activity of laccase and NADH-DCIP reductase were studied in sludge sample which were collected before and after the dye decolorization. The collected sludgecrushedand harvested in $50 \mathrm{mM}$ phosphate buffer $(\mathrm{pH}$ 7.4) and homogenized it in homogenized cup at $4^{\circ} \mathrm{C}$. The Homogenized samples were centrifuged (8000 rmp at $4^{\circ} \mathrm{C}$ for $20 \mathrm{~min}$ ) and supernatant of sludge was used as enzyme source.The Activity of laccase was assayed spectrophotometrically, where in reference blanks added all components except the enzyme $(0.2 \mathrm{ml})$. The volume of reaction mixture was adjusted by the respective buffer. One unit of an enzyme activity was measured as change in the absorbance per min.The reaction mixture for laccase activity contain $10 \%$ ABTS in $50 \mathrm{mM}$ acetate buffer ( $\mathrm{pH} \mathrm{4.8)}$ and activity determined by measure oxidation of ABTS at 420 nm.In the NADH-DCIP reductase activity measured DCIP reductionand the reduction calculated using the extinction coefficient of $19 \mathrm{mMcm}^{-1}$.

\subsection{Decolorization and degradation analysis}

Hitachi UV- Vis spectrophotometer (UV 2800) used for UV-vis spectral analysis and its absorption spectrum (400 $800 \mathrm{~nm}$ ) changes were recorded. Sample of the supernatant were obtained at initial $(0 \mathrm{~h})$ and after decolorization used for spectral analysis.

\subsection{Extraction of the metabolites}

The decolorized sample was centrifuged at $4000 \mathrm{rpm}$ for 15 min after decolorization of dyes. The supernatant obtained was used to equal volume of ethyl acetate used for extraction of metabolites. The extract was dry over anhydrous sodium sulfate and evaporates it.The metabolite residue obtained were dissolved in HPLC grade methanol and then used for analytical studies.

\subsection{Analytical procedures}

Supernatant of the decolorized sample was extracted using ethyl acetate in 1:1 proportion and concentrated using rotary evaporator. This concentrated solution was dried and the dry residue obtained was dissolved in HPLC grade methanol and then used for analysis of FTIR, HPLC and GCMS.The HPLC and FTIR techniques were described as per the earlier report [21]. GC-MS analysis for the identification of metabolites formed after degradation was carried out using a QP2010 gas chromatography coupled with mass spectroscopy (Shimadzu). NIST spectral library stored in computer software (version 1.10 beta, Shimadzu) of the GCMS was used for comparison of mass spectra of degradation metabolites and retention times.

\section{Results and Discussion}

\subsection{Decolorization of textile dyes by anactivated sludge}

Activated sludge process alone has been used for the treatment of a variety of industrial wastewaters containing dyes and colored compounds. For the study use sludge which were activated in the lab. Initial sludge had $<150 \mathrm{ml}^{-}$ ${ }^{1}$ numbers of cells, after fifteen days activation of this sludge bacterial count were increased up to $<300 \mathrm{ml}^{-1}$ numbers of cells.An activated sludge decolorized tested threetextile reactive dyes tested. The activated sludge decolorized three textile dyes Reactive Red 198, Reactive Orange HE2R and Navy Blue HE2R. An activated sludge decolorized Reactive Red 198, Reactive Orange HE2R and Navy Blue HE2R (13, 17 and $8 \%$ respectively)at static condition within $120 \mathrm{~h}$, without any carbon source. The bacterial culture was unable or slow to decolorize the dye in absence of co-substrate,

\section{Volume 5 Issue 4, April 2016}




\section{International Journal of Science and Research (IJSR) \\ ISSN (Online): 2319-7064 \\ Index Copernicus Value (2013): 6.14 | Impact Factor (2015): 6.391}

which indicates that availability of supplementary carbon source to be necessary for growth and decolorization of dyes.

Dyes are deficient in carbon content for the growth of organisms and biodegradation without any extra available carbon source had found to be very difficult [23]. Decolorization occurred only when suitable sources of carbon and nitrogen were available in the medium.In decolorization study Reactive Orange HE2R showed maximum decolorization, hence select for the further study.

\subsection{Effect of glucose and yeast extract on Reactive Orange HE2R decolorization}

Once Glucose $(0.1 \%)$ was added in activated sludge $51 \%$ decolorization of dye observed within $24 \mathrm{~h}$ at static condition. When yeast extract used as a sole carbon and nitrogen source 98\% decolorization of Reactive Orange HE2R was observed in 24 hat static condition. Decolorization of these dyes with yeast extract resulted in better decolorization efficiency compared to glucose. The yeast extract was the most effective carbon-nitrogen source in decolorization of reactive dyes by bacterial consortia [24].

\subsection{Repeated decolorization by activated sludge}

In repeated decolorization study all decolorization set performed in three times and carried out addition of yeast extract. This ability of the sludge to decolorize dye was calculated by taking absorbance at $490 \mathrm{~nm}$ after every degradation cycle. First cycle of complete decolorization was observed after the addition of Reactive Orange HE2R into the activated sludge in $24 \mathrm{~h}$. The same sludge used for the nextten cycles. These results indicate the activated sludge efficiently and complete decolorized dye up to six cycles then reduction in decolorization was observed up to ten cycles. So the concluded that activated sludge decolorization activity towards textile dye achieved up to six days.

\subsection{Enzymatic analysis}

Result (Table 1) indicates that difference between the enzyme activities of control cells and sludge cells obtained after decolorization of Reactive Orange HE2R. Laccase and NADH-DCIP reductase were found to be in control cells. The activities of laccase and NADH-DCIP reductase as significantly increase in the sludge cells obtained after decolorization. These indicated laccase and NADH-DCIP enzyme may responsible for dye decolorization as well as dye degradation. In the case of enzymatic remediation of azo dyes, azo reductases and laccases seem to be the most promising enzymes. Laccase have been shown to decolorize a wide range of industrial dyes [25] and NADH-DCIP reductase has been reported for the biotransformation of dyes [26].

\subsection{UV-Vis spectral analysis}

The Beer-Lambert law states that the absorbance of a solution is directly proportional to the concentration of the absorbing species in the solution and the path length. Thus, for a fixed path length, UV-Vis spectroscopy can be used to determine the concentration of the absorber in a solution. The UV-Vis spectrophotometer may be used as a detector for HPLC. The presence of an analyte gives a response assumed to be proportional to the concentrationUV-Visible spectroscopy measures the response of a sample to ultraviolet and visible range of electromagnetic radiations. Molecules and atoms have electronic transitions while most of the solids have interband transitions in the UV and Visible range. The most important kind of UV-Vis Spectroscopy is dispersion based spectroscopy. It involves a dispersive medium like prism or grating to separate the different wavelengths.UV-Vis spectroscopy is routinely used in analytical chemistry for the quantitative determination of different analytes, such as transition metal ions, highly conjugatedorganic compounds, and biological macromolecules.

Decolorization of Reactive Orange HE2R has been confirmed by UV-Vis spectral analysis (Figure 1). Spectrophotometrically analysis of the Reactive Orange HE2R, showed maximum absorbance at $490 \mathrm{~nm}$ and the decrease in the absorbance of samples which was withdrawn after decolorization. This result indicates the color of dye remove by an activated sludge may be largely attributed not only decolorized but also degraded.

\subsection{Fourier Transform Infrared Spectroscopy (FTIR) analysis}

The principle of FTIR is that the gas to be analyzed is led through a cuvette with an IR light source at one end that is sending out scattered IR light and a modulator that "cuts" a infra red light into different wave lengths. At the other end of the cuvette the detector is measuring the amount of IR light pass through the cuvette. Results of FTIR analysis of dye and metabolites obtained after decolorization by an activated sludge showed various peaks.

The FTIR spectrum of control Reactive Orange HE2R displays the peaks at $3364.56 \mathrm{~cm}^{-1}$ and $2946.03 \mathrm{~cm}^{-1}$ showed $\mathrm{N}=\mathrm{O}$ stretching of nitrites overtones and $\mathrm{CH}$ stretching of asymmetric alkanes respectively. A peak at $2833.96 \mathrm{~cm}^{-1}$ showed CH stretching of ether, a peak at2507.24 $\mathrm{cm}^{-1}$ for $\mathrm{NH}$ stretching of charged amines. The peaks at 1630.69 , 1452.21, 1414.68, 1032.45 and $670 \mathrm{~cm}^{-1}$ indicated $\mathrm{N}=\mathrm{N}$ stretching of azo compound, CC stretching of multiple bond aromatic compound, $\mathrm{CH}$ deformation of alkenes, $\mathrm{C}=\mathrm{O}$ stretching of sulphonic acid or $\mathrm{C}-\mathrm{OH}$ stretching of secondary alcohol and $\mathrm{CH}$ deformation of di-substituted alkenes respectively.

The FTIR spectrum of degradation metabolites of Reactive Orange HE2R by an activated sludge showed a peak at $3418.9 \mathrm{~cm}^{-1}$ for $\mathrm{NH}$ stretching of secondary amine and a peak at $2923.5 \mathrm{~cm}^{-1}$ for stretching of alkanes. The peaks at1574.8, 1410.6 and $1019 \mathrm{~cm}^{-1}$ showed $\mathrm{NO}_{2}$ stretching of $\alpha$ halogen-O-nitro compounds, $\mathrm{CH}$ deformation of alkenes and $\mathrm{CHO}$ stretching of primary alcohol respectively. It indicates formation of secondary amines, alkanes, alkenes nitro compound and primary alcohol after decolorization and degradation (Figure 2).

\section{Volume 5 Issue 4, April 2016




\section{International Journal of Science and Research (IJSR) \\ ISSN (Online): 2319-7064 \\ Index Copernicus Value (2013): 6.14 | Impact Factor (2015): 6.391}

The FTIR study, the samples obtained after decolorization of Reactive Orange HE2R lack a peak at $1630.69 \mathrm{~cm}^{-1}$ present in the dye spectrum, it indicates the breakdown of azo bond during the dye degradation process (Figure 3).

\subsection{High Performance Liquid Chromatography (HPLC) analysis}

HPLC istechnique which use for separating the mixture of compounds on the basis of polarity. It is used to analyze, identify, purify and quantify compounds. It has a mobile phase, a stationary phase and detector. The mobile phase is continuously pumped at a fixed flow rate through the system and mixed by the pump. The injector is used to introduce a plug of a sample into the mobile phase without having to stop the mobile phase flow and without introducing air into the system. The mixture of components is carried in a narrow band to the top of the column. Some compounds in the sample mixture will have greater preference for stationary phase than the mobile phase and will be retained in the column longer.

High performance liquid chromatography analysis of Reactive Orange HE2R and metabolites extracted after decolorization showed the different retention times peaks. Reactive Orange HE2R showed major peak at retention time 2.384 min (Figure4), whereas metabolites extracted after decolorization showed additional five peaks at retention times 2.238, 2.745, 2.931 and 3.20 min (Figure5). HPLC analysis confirmed the degradation of Reactive Orange HE2R in to different metabolites.

\subsection{Gas Chromatography and Mass Spectrometry}

The GC-MS instrument separates chemical mixtures (the GC component) and identifies the components at a molecular level (the MS component). The degradation of Reactive Orange HE2R was analyzed by GC-MS for tentative identification of unknown metabolites. The probable dye degradation pathway is shown in figure 6 .

The possible compounds of Reactive Orange HE2R degradation by activated sludge, three had matches in relation to metabolites present in the sample, viz. amino ethyl pyridine, 2-amino butane 4-sulpho aniline (Molecular Weight 167, Retention Time $16.467 \mathrm{~min}$ ), amino ethyl-2sulpho aniline and sulphoaniline (Molecular Weight $(\mathrm{m} / \mathrm{z}$ ) 154, Retention Time $19.433 \mathrm{~min})$.

\section{Conclusions}

Activated textile industry sludge is nothing but an increase in number of microorganisms that are adapted to textile dyes. The overall approach of bioremediation is to enhance natural process of biodegradation by native organisms. For that purpose we activate textile industry sludge. An activated sludgehas an efficient tool for the removal of azo dye and in particular, Reactive Orange HE2R.Thus,complete decolorization can be obtained through activated sludge treatment and the same activated sludge can be used for the continuous decolorization of same dye to sevendays. To knowledge this work may be first report regarding the Reactive Orange HE2R degradation using an activated sludge, showing efficient decolorization, capacity to repetitively decolorization and the presence of biotransformation enzymes in dye degradation. However, the pilot studies are needed to apply this decolorization and degradation tool for the effluent contaminated with textile dyes on large scale.

\section{Acknowledgement}

Pratibha S. Patil expresses gratitude to DST-SERB (Science and Engineering Research Board), New Delhi, India for Fast Track Young Scientists Fellowship.

\section{References}

[1] Correia, V. M., Stephenson, T. and Judd, S. (1994). Characteristics of textile wastewaters-a review.Environmental Technology, 15, 917-929.

[2] Delee, W., O’Niell, C., Hawkcs, F. R. andPinheiro, H. M. (1998). Anaerobic treatment of textile effluents: a review. Journal of Chemical Technology and Biotechnology, 73, 323-325.

[3] Cooper, P. (1993). Removing color from dye house waste waters-a critical review of technology available.Society of Dyers and Colorists,109, 97-100.

[4] Ajayi, S. O. andOsibanjo, O. (1980). The state of environment in Nigeria pollution studies of textile industries in Nigeria monogram, 1, 76-86.

[5] Arden, E. and Lockett, W. T. (1914). Experiments on the oxidation of sewage without the aid of filters.Journal of the Society of Chemical Industry, 33, 523-539.

[6] Pagga, U. andTaeger, K. (1994). Development of a method for adsorption of dyestuffs on activated sludge. Water Research, 28, 1051-1057.

[7] Royer, G., Yerushalmi, L., Rouleau, D. andDesrochers, M. (1991). Continuous decolorization of bleached kraft effluents by Coriolusversicolorin the form of pellets.Journal of Industrial Microbiology,7, 269-278.

[8] Seshadri, S., Bishop, P. L. and Agha, A. M. (1994). Anaerobic/aerobic treatment of selected azo dyes in wastewater. Waste Management, 14, 127-137.

[9] Zimmerman, T., Kulla, H. andLeisinger, T. (1982). Properties of purified Orange II azoreductase, the enzyme initiating azo dye degradation by Pseudomonas KF46.Europian Journal of Biochemistry, 129, 197-203.

[10] Nachiyar, C. V. andRajkumar, G. S. (2003). Degradation of a tannery and textile dye, Navitan Fast Blue S5R by Pseudomonas aeruginosa.World Journal of Microbiology and Biotechnology, 19, 609-614.

[11] Stolz, A. (2001). Basic and applied aspects in the microbial degradation of azo dyes.Applied Microbiology and Biotechnology, 56, 69-80.

[12] Jiang, H. and Bishop, P. L. (1994).Aerobic biodegradation of azo dyes in biofilms.Water Science and Technology, 29, 525-530.

[13] Churchley, J. H., Greaves, A. J., Hutchings, M. G., James, A. E. and Phillips, D. A. S. (2000). The development of a laboratory method for quantifying the bioelimination of anionic water soluble dyes by a biomass.Water Research,34, 1673-1679.

[14] Aksu, Z. (2001). Reactive dye bioaccumulation by Saccharomyces cerevisiae.Process Biocheistry, 38, 1437-1444. 


\section{International Journal of Science and Research (IJSR) \\ ISSN (Online): 2319-7064 \\ Index Copernicus Value (2013): 6.14 | Impact Factor (2015): 6.391}

[15] Ong, S., Toorisaka, E., Hirata, M. andHano, T. (2005). Decolorization of azo dye (Orange II) in sequential UASB-SBR system. Separation and Purification Technology, 42, 297-302.

[16] Panswad, T. andLuangdilok, W. (2000). Decolorization of reactive dyes with different molecular structures under different environmental conditions. Water Research,34, 4177-4184.

[17] Chen, K. C., Huang, W. T., Wu, J. Y.andHoung, J. Y. (1999). Microbial decolorization of azo dyes by Proteus mirabilis.Journal of Industrial Microbiology and Biotechnology, 23, 686-690.

[18] Chang, J. S., Chou, C., Lin, Y., Ho, J. and Hu, T. L. (2001). Kinetic Characteristics of bacterial azo dye decolorization by Pseudomonas luteola.Water Research, 35, 2041-2850.

[19] Yu, J., Wang, X. and Yue, P. L. (2001). Optimal decolorization and kineticmodeling of syntheticdye by Pseudomonas strains. Water Research, 35, 3579-3586.

[20] Kalyani, D. C., Patil, P. S., Jadhav, J. P. andGovindwar, S. P. (2007). Biodegradation of reactive textile dye Red BLI by an isolated bacterium Pseudomonas sp. SUK1.Bioresource Technology, 99, 4635-4641.

[21] Patil, P. S., Patil, V. S., Surwase, S.andJadhav, J. P. (2015). Evaluation of the efficiency of isolated bacterial consortium PMB11 in removal of color degradation and reduction of toxicity from textile dye effluent.Biologia, 70, 11-18.

[22] Talwar G. P. 1983 Hand Book of practical immunology. Vikas Publishing House, Pvt. Ltd, New Delhi.

[23] Padmavathy, S., Sandhya, S., Swaminathan, K., Subramanium, Y. V., Chakrabarti, T. andKaul, S. N. (2003). Aerobic decolorization of reactive azo dyes in presence of various cosubstrates.Chemical and Biochemical Engineering Quarterly, 17:147-51.

[24] Patil, P. S., Phugare, S. S., Jadhav, S. B. andJadhav, J. P. (2010). Communal action of microbial cultures for Red HE3B degradation.Journal of Hazardous Materials, 181, 263-270.

[25] Reyes, P., Pickard, M. A. and Vazquez-Duhal, R. (1999). Hydroxybenzotriazole increases the range of textile dyes decolorized by immobilized laccase. Biotechnology Letters, 21, 875-880.

[26] Salokhe, M. D. andGovindwar, S. P. (1999). Effect of carbon source on the biotransformation enzymes in Serratiamarcescens.World Journal of Microbiology and Biotechnology,15, 229-232.

Table 1: Enzyme activities before decolorization and after decolorization

\begin{tabular}{|l|l|l|}
\hline \multicolumn{1}{|c|}{ Enzyme } & Before Decolorization & $\begin{array}{c}\text { After } \\
\text { Decolorization }\end{array}$ \\
\hline Laccase $^{\mathrm{a}}$ & $0.027 \pm 0.005$ & $0.118 \pm 0.012$ \\
\hline DCIP reductase $^{\mathrm{b}}$ & $0.850 \pm 0.001$ & $1.480 \pm 0.086$ \\
\hline
\end{tabular}

${ }^{\mathrm{a}}$ Enzyme unit $\mathrm{min}^{-1} \mathrm{mg}$ protein ${ }^{-1}$, ${ }^{\mathrm{b}} \mu \mathrm{g}$ DCIP reduced $\mathrm{min}^{-1} \mathrm{mg}$ protein $^{-1}$

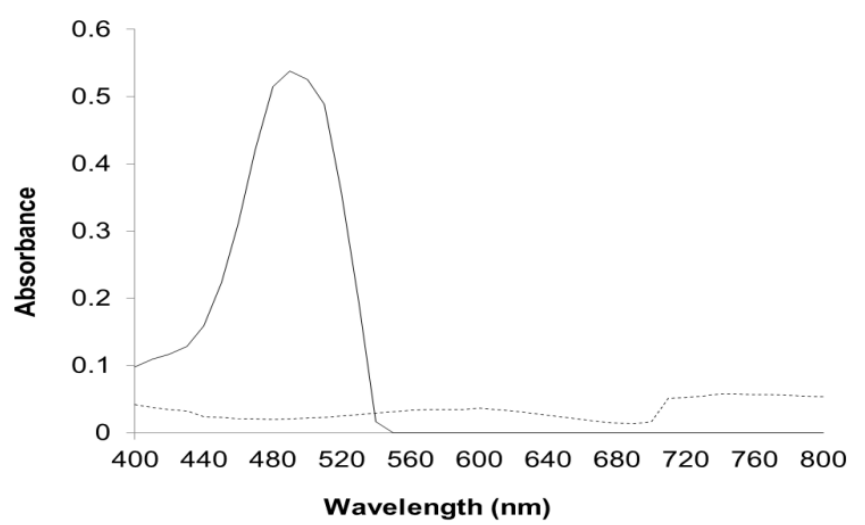

Figure 1: UV -Vis analysis of Reactive Orange HE2R before and after decolorization

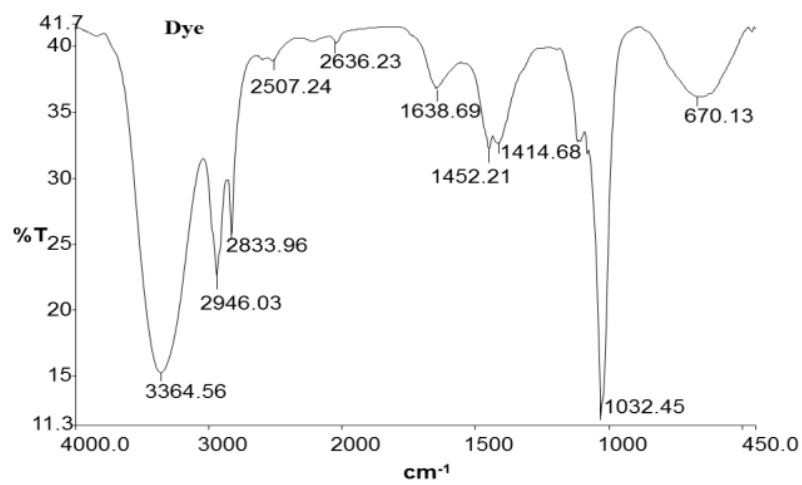

Figure 2: FTIR analysis of Reactive Orange HE2R

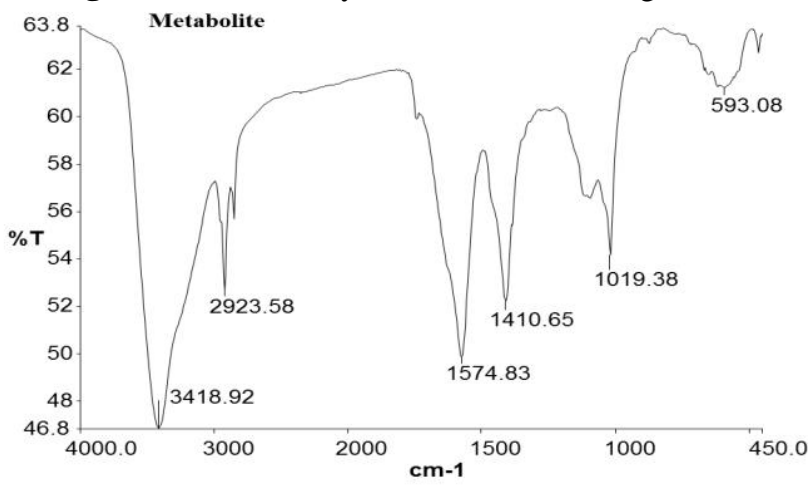

Figure 3: FTIR analysis of degradation metabolites of Reactive Orange HE2R by activated sludge

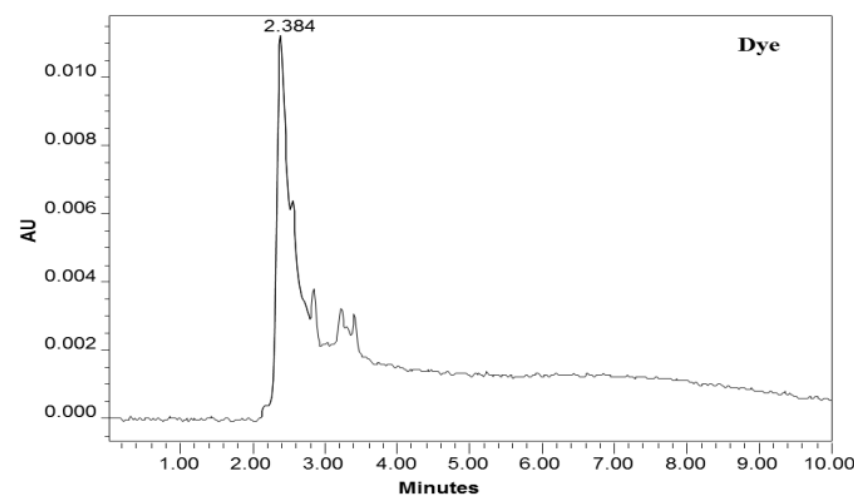

Figure 4: HPLC elution profile of Reactive Orange HE2R 


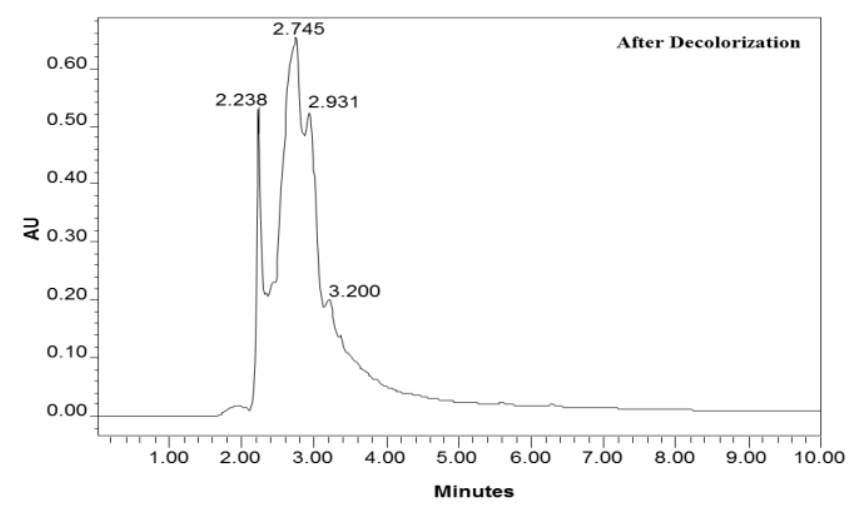

Figure 5: HPLC elution profile of degradation metabolites of Reactive Orange HE2R activated sludge

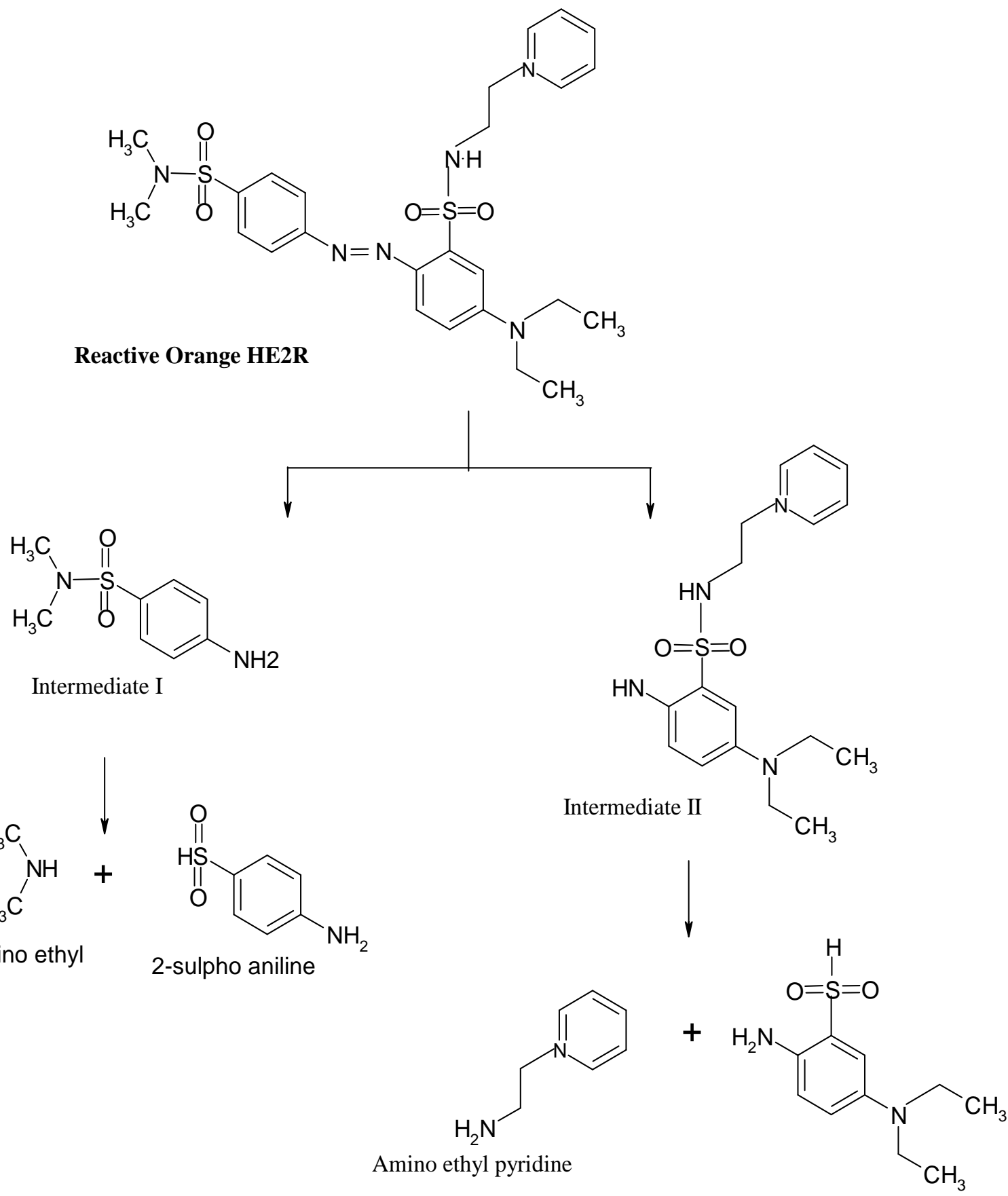

2-amino butane 4-sulpho aniline

Figure 6: Proposed pathway of biodegradation of reactive Orange HE2R by activated sludge 